\title{
Migration of an Intracranial Subdural Hematoma to the Spinal Subdural Space: A Case Report
}

\author{
O Ik Kwon, Dong Wuk Son, Young Ha Kim, Young Soo Kim, Soon Ki Sung, \\ Sang Weon Lee, Geun Sung Song
}

\author{
Department of Neurosurgery, Pusan National University Yangsan Hospital, \\ Pusan National University School of Medicine, Yangsan, Korea
}

\begin{abstract}
A 57-year-old man complained of severe lower back pain and radicular pain in both legs for 1 week after falling from a ladder. Magnetic resonance imaging (MRI) of the spine showed a subdural hematoma (SDH), which was surgically removed. The patient had no back pain or the radicular leg pain at 2 weeks post-surgery. However, he complained of diffuse headaches upon follow-up. Brain computed tomography (CT) and MRI revealed an intracranial SDH, which was immediately removed by surgery. During his 1-year follow-up, he reported that the pain had resolved without recurrence. Simultaneous spinal and intracranial $\mathrm{SDH}$ are rare and no standard treatment exists for this condition. This case suggests that it is possible that an intracranial SDH can migrate into the cerebrospinal fluid (CSF) space through an arachnoid tear. CSF circulation allows the intracranial SDH to enter subarachnoid spaces encasing the spinal cord. In order to prevent irreversible damage, surgical intervention should be considered for case of spinal SDH with progressive neurological deficits.
\end{abstract}

Key Words: Cerebrospinal fluid $\cdot$ Intracranial subdural hematoma $\cdot$ Spinal subdural hematoma $\cdot$ Spinal injuries $\cdot$ Subarachnoid space

\section{INTRODUCTION}

With technical advancements in magnetic resonance imaging (MRI), the reported incidence of spinal subdural hematoma (SDH) has been steadily increasing ${ }^{3,9}$. However, spinal SDH is still considered a rare hemorrhagic disorder ${ }^{7}$. Furthermore, simultaneous spinal and intracranial SDHs are extremely rare, having been reported in only about 35 cases to date ${ }^{6}$. This case report describes successful surgical treatment of simultaneous spinal and intracranial SDH.

\section{CASE REPORT}

The patient is a 57 -year-old man, had been experiencing

- Received: May 14, 2015 - Revised: June 24, 2015

- Accepted: July 1, 2015

Corresponding Author: Dong Wuk Son, MD, PhD

Department of Neurosurgery, Pusan National University Yangsan Hospital,

20 Geumo-Ro, Mulgeum-eup, Yangsan-si, Gyeongsangnam-do

50612 , Korea

Tel: +82-55-360-2126, Fax: +82-55-360-2156

E-mail: oik99@naver.com

®This is an Open Access article distributed under the terms of the Creative Commons Attribution Non-Commercial License (http://creativecommons.org/ licenses/by-nc/3.0/) which permits unrestricted non-commercial use, distribution, and reproduction in any medium, provided the original work is properly cited. severe low back pain (Numeric Rating Scale: 5) and radicular pain in both legs for 1 week prior to visiting our institute. During this week, the patient did not take any medication. His symptoms were likely due to a fall, which had occurred 2 weeks prior. Upon neurological examination, he had weakness in both lower extremities (Manual Muscle Test: 3/5). The patient was alert, could orient well, and did not present any symptoms of cranial nerve palsy. Upon admission, MRI of the spine showed an elongated, lobulated mass encasing the cauda equina from L2 to S1 level. Sagittal and axial T1weighted images showed high signal intensity in the spinal subdural space. Sagittal and axial T2-weighted images showed iso-intense in this space (Fig. 1). Based on these results, partial hemilaminectomy was performed (L3 subtotal, L5 left). At the time of surgery, the epidural space appeared normal without any observable hematoma. The dura mater was bluish in color and some bulging was observed. After incisions into dura and arachnoid membrane, the hematoma was identified and removed by aspiration and irrigation from the lower and upper levels of the laminectomy area. After successful removal of hematoma, the spinal cord and cauda equina appeared normal (Fig. 2). Post-operative spinal MRI performed 1 week later showed no sign of continued spinal SDH (Fig. 3).

Two weeks after the operation, the patient began experiencing diffuse headaches. To determine the cause of these headaches, brain computed tomography (CT) and MRI were per- 

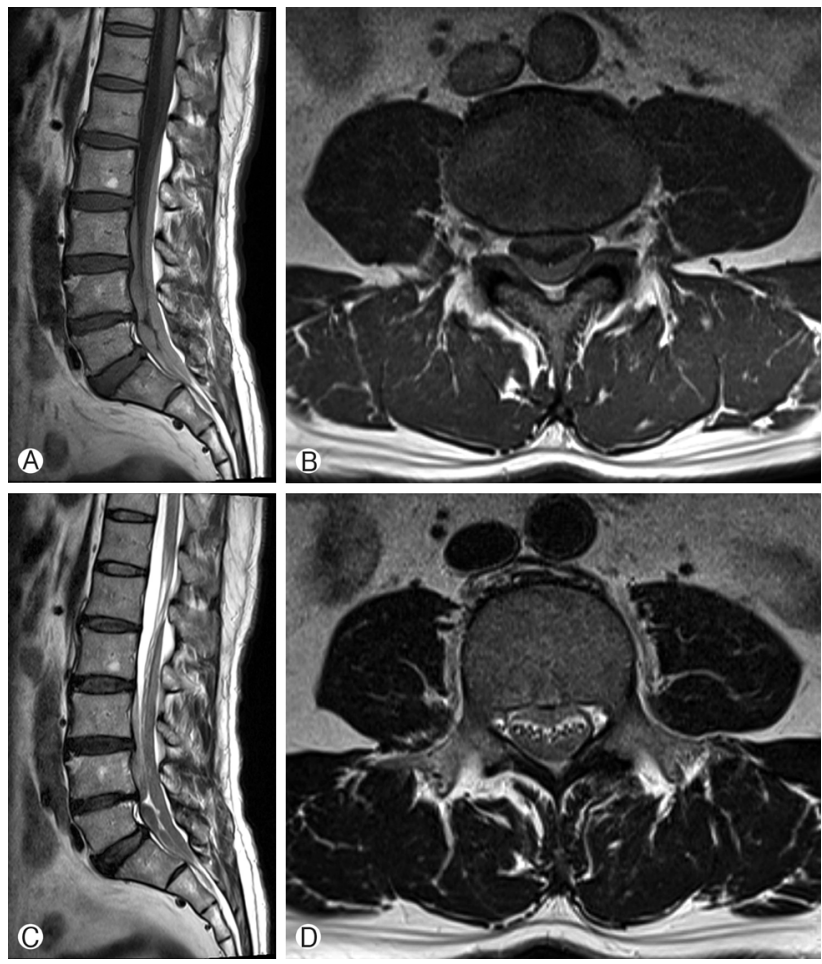

Fig. 1. Pre-operative $\mathrm{T} 1$-weighted magnetic resonance images: sagittal (A) and axial (B) views. T2-weighted magnetic resonance images: sagittal (C) and axial (D) views. The images revealed a spinal subdural hematoma between L2 and S1.

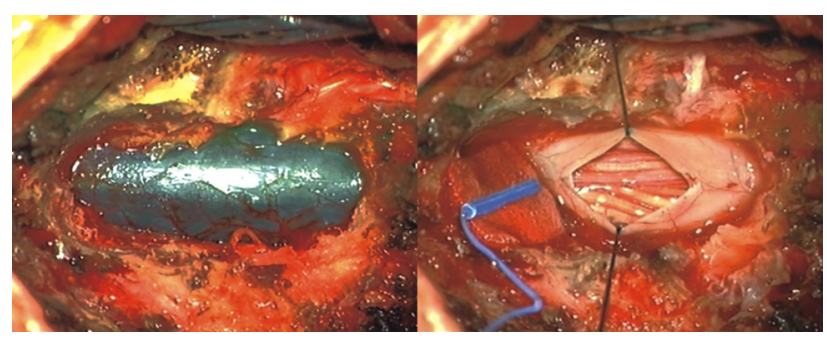

Fig. 2. Intra-operative photograph shows the dura mater, which is bluish in color with some bulging. After excision of the dura and arachnoid membrane, the hematoma was revealed, and removed by aspiration and irrigation from the lower and upper levels of the laminectomy area.

formed immediately. T1-weighted MRI of the brain showed iso-intense, while T2-weighted MRI showed low signal intensity in the left cerebral convexity and a midline shift to right with compression of the left lateral ventricle due to mass effect (Fig. 4). To evacuate the intracranial SDH, a burr-hole trephination with irrigation and drainage was conducted. Postoperative CT showed no residual hematoma (Fig. 5). Follow-up at 1 year after this surgery revealed that the patient's symptoms had resolved completely without any recurrence.

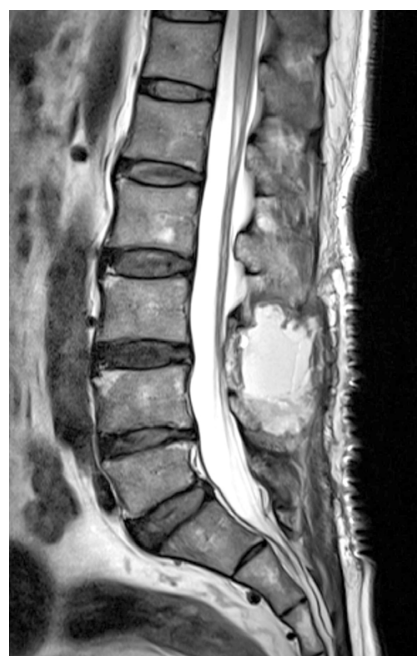

Fig. 3. Sagittal T2-weighed magnetic resonance image reveals remarkable resolution of the hematoma after decompressive laminectomy.
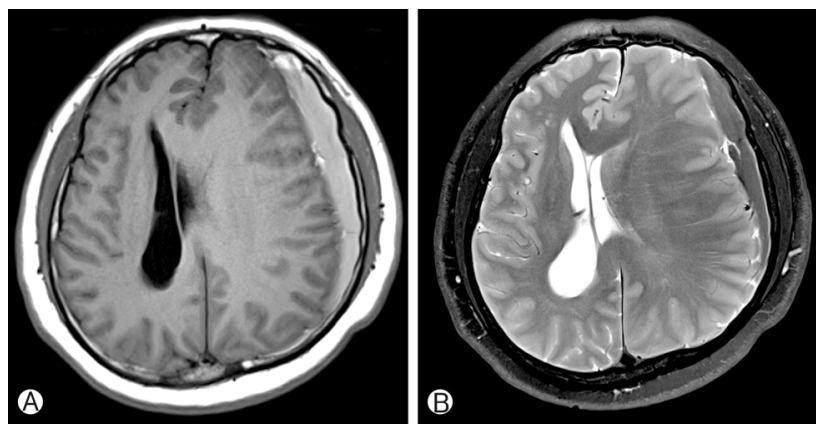

Fig. 4. Pre-operative $\mathrm{T} 1$-weighted $(\mathrm{A})$ and $\mathrm{T} 2$-weighted $(\mathrm{B})$ magnetic resonance images of the brain. The $\mathrm{T} 1$ - and $\mathrm{T} 2$-weighted images show iso- and low signal intensity in the left cerebral convexity, respectively, along with a midline shift to the right and compression of the left lateral ventricle due to a mass effect.

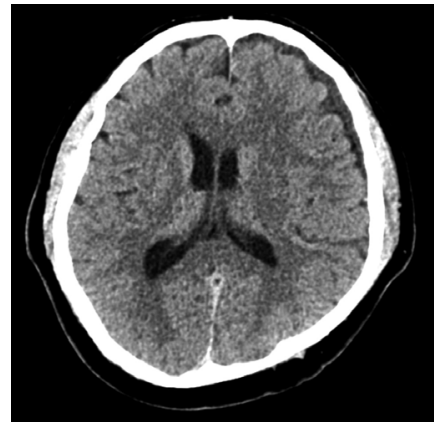

Fig. 5. Post-operative computed tomography scan revealing the complete disappearance of the left subdural hematoma.

\section{DISCUSSION}

Spinal SDH is a rare hemorrhagic disorder ${ }^{6}$. Factors that predispose an individual to spinal SDH include trauma, surgery, lumbar puncture, spinal tumor, alcohol abuse, and coa- 
gulopathy ${ }^{2,7,12)}$. The pathophysiology underlying the simultaneous development of spinal and cranial SDH is poorly understood. It is possible that blood from the cranium leaks into the spine, or there may be two unique sources of bleeding.

At least two theories can explain the development of simultaneous spinal and cranial SDHs in our patient. The first theory is that the spinal SDH was caused by rupturing of vessels in the spinal space ${ }^{4,8)}$. In this scenario, trauma due to falling from the ladder would be an important factor in spinal SDH development. However, since the spinal space does not contain any major blood vessels or bridging veins that can act as a source for a spinal $\mathrm{SDH}^{8)}$, the incidence of spinal $\mathrm{SDH}$ is significantly lower than that of cranial SDH. The second theory is related to "the dilutional and water hammer like effect" previously proposed by Moscovici et al. ${ }^{10)}$ and Bortolotti et al. ${ }^{1)}$. Moscovici et al. ${ }^{10)}$ reported a case of an 88-year-old man who received conservative management of an intracranial SDH due to head trauma. He subsequently developed cauda equina syndrome and laminectomy was performed. Bortolotti et al. ${ }^{1)}$ reported a case of a 23-year-old woman who initially had blunt head trauma with an intracranial SDH. The patient began experiencing back pain 4 days after head injury. MRI revealed a spinal SDH. It is possible that there may be two unique sources of bleeding, but these cases suggest that cerebrospinal fluid (CSF) influx into the subdural space following a trauma-induced arachnoid tear can facilitate $\mathrm{SDH}$ migration into other parts of the spinal cord. We also hypothesized that an intracranial SDH can migrate into the CSF space through arachnoid tear. CSF circulation pathway can allow an intracranial SDH to enter the subarachnoid spaces encasing the spinal cord. Therefore, spinal SDH may occur as a sequel of cranial $\mathrm{SDH}$ via migration. Although we cannot completely exclude the possibility of intracranial hematoma result from cerebral hypotension induced by spinal decompression surgery, the patient showed no symptom of CSF leakage after surgical intervention. Furthermore, the age of intracranial SDH was estimated as more than 2 weeks on CT and MRI. Therefore, we think that intracranial SDH can migrate into the CSF space and enter the subarachnoid spaces encasing the spinal cord.

Regardless to the mechanisms of action, it was difficult to decide on spinal SDH treatment. Treatment options include conservative therapy and surgical intervention ${ }^{5)}$. Spontaneous resolution of spinal SDH has been reported previously,11), but, a meta-analysis demonstrates that most patients (85.5\%) with symptomatic spinal SDHs undergo decompression surgery for symptom alleviation ${ }^{7}$. In the present case, surgery was performed to remove the spinal $\mathrm{SDH}$, based on the aggravate symptoms, including gait disturbance and back pain (Numeric Rating Scale: 8). Thus, although patients with mild neurologic symptoms are likely to benefit from conservative therapy, prompt surgical intervention should be performed when the spinal SDH is massive or clinical symptoms are progressive.

\section{CONCLUSION}

We report a rare case of spinal SDH concurrent with intracranial SDH after trauma. Our case suggests the possibility that an intracranial SDH can migrate into the CSF space through an arachnoid tear and via CSF circulation, can enter the subarachnoid spaces encasing the spinal cord.

\section{REFERENCES}

1. Bortolotti C, Wang H, Fraser K, Lanzino G: Subacute spinal subdural hematoma after spontaneous resolution of cranial subdural hematoma: causal relationship or coincidence? Case report. J Neurosurg 100:372-374, 2004

2. Boukobza M, Haddar D, Boissonet M, Merland JJ: Spinal subdural haematoma: a study of three cases. Clin Radiol 56:475480, 2001

3. Domenicucci M, Ramieri A, Ciappetta P, Delfini R: Nontraumatic acute spinal subdural hematoma: report of five cases and review of the literature. J Neurosurg 91:65-73, 1999

4. Hung KS, Lui CC, Wang CH, Wang CJ, Howng SL: Traumatic spinal subdural hematoma with spontaneous resolution. Spine (Phila Pa 1976) 27:E534-538, 2002

5. Kim K, Katsuno M, Isu T, Mishina M, Yoshida D, Kobayashi $\mathrm{S}$, et al: Concomitant cranial and lumbar subdural hematomas -case report-. Neurol Med Chir (Tokyo) 50:402-404, 2010

6. Kokubo R, Kim K, Mishina M, Isu T, Kobayashi S, Yoshida $\mathrm{D}$, et al: Prospective assessment of concomitant lumbar and chronic subdural hematoma: is migration from the intracranial space involved in their manifestation? J Neurosurg Spine 20: 157-163, 2014

7. Kreppel D, Antoniadis G, Seeling W: Spinal hematoma: a literature survey with meta-analysis of 613 patients. Neurosurg Rev 26:1-49, 2003

8. Leber KA, Pendl G, Kogler S, Kammerhuber F, Ebner F: Simultaneous spinal and intracranial chronic subdural hematoma. Case illustration. J Neurosurg 87:644, 1997

9. Lecouvet FE, Annet L, Duprez TP, Cosnard G, Scordidis V, Malghem J: Uncommon magnetic resonance imaging observation of lumbar subdural hematoma with cranial origin. J Comput Assist Tomogr 27:530-533, 2003

10. Moscovici S, Paldor I, Ramirez de-Noriega F, Itshayek E, Shoshan Y, Spektor S, et al: Do cranial subdural hematomas migrate to the lumbar spine? J Clin Neurosci 18:563-565, 2011

11. Wong ST, Yuen MK, Fok KF, Yuen SC, Yam KY, Fong D: Redistribution of hematoma to spinal subdural space as a mechanism for the rapid spontaneous resolution of posttraumatic intracranial acute subdural hematoma: case report. Surg Neurol 71:99-102, 2009

12. Yamaguchi S, Kurisu K, Arita K, Takeda M, Tani I, Araki O: Simultaneous cranial and spinal subdural hematoma. Neurol Med Chir (Tokyo) 45:645-649, 2005 